УДК 621.822

Д-р техн. наук А.В. Гайдамака (НТУ «ХПІ»)

Doct. of techn. sciences A.V. Gaydamaka

\title{
НАДІЙНІСТЬ ЦИЛІНДРИЧНИХ РОЛИКОПІДШИПНИКІВ БУКС ВАГОНІВ І ЛОКОМОТИВІВ
}

\section{RELIABILITY OF CYLINDRICAL ROLLER BEARINGS CARS AND LOCOMOTIVES}

Аналіз публікацій. Циліндричні роликопідшипники букс вагонів i локомотивів відносять до важконавантажених нешвидкісних підшипників, які працюють 3 радіальним та осьовим навантаженням, більшим від десятої частини допустимої радіальної вантажності, і частотами обертання, меншими від третини граничних. Найбільш масові циліндричні роликопідшипники букс колісних пар вагонів мають недостатню надійність [1]. Серед можливих відмов їх деталей шосту частину становлять контактно-втомні пошкодження (рис. 1).

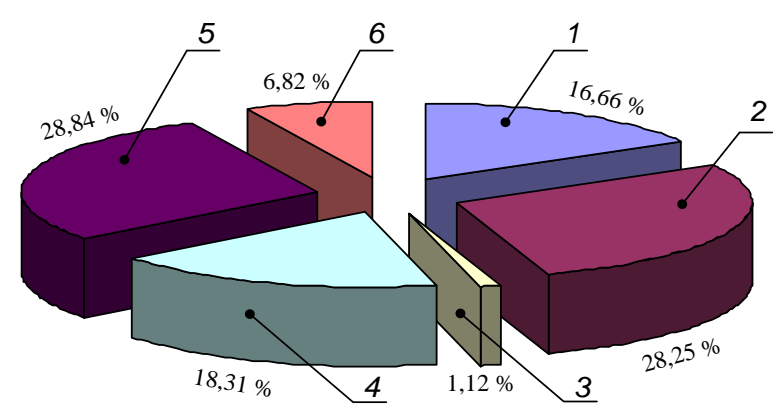

Рис. 1. Розподіл пошкоджень роликопідшипників букс вагонів:

1 - втомні пошкодження кілець та роликів; 2 - корозійні пошкодження кілець та роликів; 3 - тріщини кілець та роликів; 4 - знос та порушення розкарбування латунного сепаратора; 5 - знос торців роликів та бортів кілець; 6 - інші пошкодження

Одним 3 основних напрямів підвищення ресурсу підшипників кочення $є$ зменшення контактних напружень згідно 3 виразом

$$
\frac{L}{L^{*}}=\left(\frac{C}{C^{*}}\right)^{10 / 3}=\left(\frac{F_{0}}{F_{0}^{*}}\right)^{10 / 3}=\left(\frac{\sigma_{\max }}{\sigma_{\max }^{*}}\right)^{20 / 3},
$$

де $L, \quad L^{*}, C, \quad C^{*}, \quad F_{0}, \quad F_{0}^{*}, \quad \sigma_{\max }, \sigma_{\max }^{*}-$ відповідно ресурс, динамічна вантажність, навантаження центрального ролика, максимальне напруження типового i вдосконаленого підшипників.

Найбільш перспективним шляхом зменшення контактних напружень при зберіганні існуючих габаритів роликопідшипника вважається збільшення кількості роликів [2]. При цьому необхідно змінити конструкцію сепаратора, розрахувати його міцність, оцінити надійність підшипника за можливістю 
втомного руйнування сепаратора. Однак вказаних розрахунків у вітчизняній i закордонній практиці проектування циліндричних роликопідшипників букс вагонів дотепер не існує, оскільки недостатньо теоретичних досліджень 3 кінематики та динаміки їх деталей [3, 4], а експериментальні дослідження [5-8] не повною мірою пояснюють особливості функціонування сепараторів. Отже, виникає необхідність розроблення моделей статики, кінематики, динаміки важконавантажених нешвидкісних циліндричних роликопідшипників для методів розрахунку сепараторів на втомну міцність при згині та розрахунку надійності підшипників 3 урахуванням витривалості сепаратора.

Метою дослідження є удосконалення i розроблення математичних моделей статики, кінематики, динаміки циліндричних роликопідшипників букс вагонів та локомотивів для методів розрахунку сепараторів на втомну міцність при згині та розрахунку надійності підшипників 3 урахуванням витривалості сепаратора.

\section{Основний матеріал}

Для досягнення поставленої мети необхідно розв'язати такі задачі:

•удосконалити моделі розподілу радіального навантаження;
• удосконалити моделі розподілу осьового навантаження;

- розробити модель кінематики підшипника в зоні навантаження;

- розробити модель динаміки підшипника в зоні навантаження;

- розробити метод розрахунку сепаратора на витривалість при згині;

- розробити методики розрахунку коефіцієнтів динамічності навантаження сепаратора роликами, концентрації навантаження сепаратора, концентрації напружень в сепараторі;

- розробити метод розрахунку ймовірності безвідмовної роботи підшипника 3 урахуванням витривалості сепаратора.

\section{1. Удосконалення моделі розподілу} радіального навантаження

Дано: радіальне навантаження; необхідно: уточнити розподіл радіального навантаження з урахуванням кутів контакту роликів 3 кільцями, радіального зазора, згину кілець. Ідея розв'язання - в геометричних рівняннях замість зв'язку вертикальних i радіальних переміщень контактних точок роликів 3 внутрішнім кільцем застосовано зв'язок центрів кілець і роликів; фізичні рівняння являють собою зв'язок зближень кілець i роликів 3 радіальною силою; у статичних рівняннях подано рівновагу внутрішнього кільця.

$$
\begin{gathered}
F_{1}=F_{0}\left(\cos \gamma_{1}^{\prime}+\frac{g}{\delta_{0}}\left(\cos \gamma_{1}^{\prime}-1\right)-\left(u_{\mu}-u_{b}\right)\right) \\
F_{n}=F_{0}\left(\cos \gamma_{n}^{\prime}+\frac{g}{\delta_{0}}\left(\cos \gamma_{n}^{\prime}-1\right)-\left(u_{H}-u_{b}\right)\right) . \\
F_{0}=F_{r} /\left(1+2 \sum_{i=1}^{n}\left(\cos i \gamma^{\prime}\left(\cos i \gamma^{\prime}+\frac{g}{\delta_{0}}\left(\cos i \gamma^{\prime}-1\right)-\left(u_{H}-u_{b}\right)\right)\right)\right) .
\end{gathered}
$$




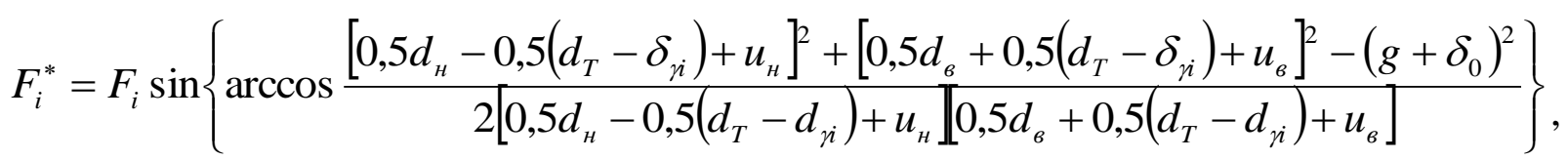

де $\delta_{0}$ - радіальний зазор; $u_{н}, u_{6}$ - деформації зовнішнього і внутрішнього кілець відповідно.

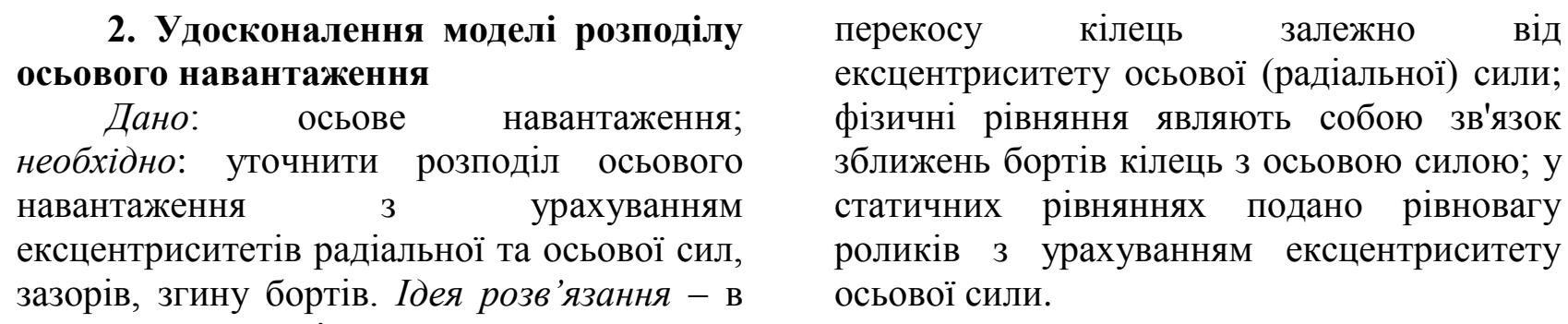
геометричних рівняннях введено кут

$$
\begin{aligned}
& \theta_{\text {в }}=\frac{12 \delta_{r r \Sigma} \cdot e_{r e}}{l_{p}^{2}}, \quad \text { де } \quad \delta_{H r \Sigma}=8,0 \cdot 10^{-5} \frac{F_{r \Sigma}^{0,9}}{l_{r}^{0,8}}, \\
& F_{0}=\kappa \cdot\left(\delta_{0}+u_{H}+u_{B}\right), F_{1}=\kappa \cdot\left(\delta_{0}+u_{H}+u_{B}-l_{1}\right), \ldots, F_{n}=\kappa \cdot\left(\delta_{0}+u_{H}+u_{B}-l_{n}\right), \\
& \kappa=\frac{F_{0}}{\delta_{0}}=\frac{F_{1}}{\delta_{0}+u_{H}+u_{B}-l_{1}}=\ldots=\frac{F_{n}}{\delta_{0}+u_{H}+u_{B}-l_{n}} . \\
& F_{1}=F_{0} \cdot\left(1-\frac{l_{1}}{\delta_{0}+u_{H}+u_{6}}\right), \ldots, F_{n}=F_{0} \cdot\left(1-\frac{l_{n}}{\delta_{0}+u_{H}+u_{6}}\right) \\
& F_{a}=F_{0} \cdot\left[1+2\left(1-\frac{l_{1}}{\delta_{0}+u_{B}+u_{H}}\right)+\ldots+2\left(1-\frac{l_{n}}{\delta_{0}+u_{B}+u_{H}}\right)\right] \\
& F_{0}=\frac{\kappa_{a} \cdot F_{a}}{z}, \quad \text { де } \kappa_{a}=\frac{z}{\left[1+2 \sum_{i=1}^{n}\left(1-\frac{l_{i}}{\delta_{0}+u_{H}+u_{H}}\right)\right]} \text {. }
\end{aligned}
$$

3. Розроблення моделей кінематики підшипника в зоні навантаження

Дано: обертання внутрішнього кільця підшипника при нерухомому зовнішньому; необхідо: уточнити кінематику підшипника 3 урахуванням конструктивних, технологічних та експлуатаційних факторів. Ідея розв'язання - встановлюються причини нерівномірності руху роликів у зоні навантаження ідельного i реального підшипників; вводиться гіпотеза про рух сепаратора; визначається швидкість сепаратора з боковим зазором в ідеальному і реальному підшипниках. 


$$
\begin{gathered}
\psi=\psi_{k}+\psi_{c}, \\
t_{\psi}=\frac{\psi_{k}+\psi_{c}}{\omega_{P \gamma}}=t_{\psi_{k}}+t_{\psi_{c}}, \\
S_{P}=\omega_{P} \cdot \frac{d_{0}}{2} \cdot\left(t_{\psi_{k}}+t_{\psi_{c}}\right), \quad S_{C}=\omega_{C} \cdot \frac{d_{0}}{2} \cdot t_{\psi_{k}} \\
\omega_{C}=\omega_{P \gamma}\left[\left(1+\frac{\psi_{c}}{\psi_{k}}\right)-\frac{2 S_{0}}{d_{0} \cdot \psi_{k}}\right] .
\end{gathered}
$$

4. Розроблення моделей динаміки підшипника в зоні навантаження

Дано: радіальне та осьове навантаження; необхідно: визначити сили взає-модії сепаратора 3 деталями підшипника. Ідея розв'язання досліджується кочення ролика всередині і на виході із зони навантаження підшипника при відсутності проковзування; вводиться гіпотеза про симетричність сил взаємо-дії сепаратора із роликами, що входять i виходять 3 зони радіального наван-таження підшипника.

4.1. Кочення ролика всередині зони навантаження без проковзування

$$
\begin{aligned}
& m \ddot{x_{c}}=F_{f_{u}}(\varphi)+F_{f_{B}}(\varphi)-F_{б н}(\varphi) \cdot \cos \beta_{\mu}-F_{б в}(\varphi) \cdot \cos \beta_{\theta} ; \\
& m \ddot{y_{c}}=m g+F_{б н}(\varphi) \cdot \sin \beta_{н}-F_{б в}(\varphi) \cdot \sin \beta_{в} ; \\
& \ddot{I \varphi_{c}}=\left[F_{f н}(\varphi)-F_{f_{B}}(\varphi)\right] \cdot \frac{D_{w}}{2}-2 \kappa \cdot F_{r}(\varphi)-F_{б н}(\varphi) \cdot h_{\mu}-F_{б в}(\varphi) \cdot h_{b} ; \\
& \frac{3}{16} m \cdot D_{w}^{2}\left(\omega_{p 1}^{2}-\omega_{p 0}^{2}\right)=\left[F_{f H}(\varphi)+F_{f \beta}(\varphi)-F_{6 н}(\varphi) \cdot \cos \beta_{\mu}-F_{6 в}(\varphi) \cdot \cos \beta_{\theta}\right] \cdot S \\
& F_{\sigma н}(\varphi)+F_{б в}(\varphi)=F_{\sigma}(\varphi)
\end{aligned}
$$

Розв'язання системи (14) - (18):

$$
\begin{aligned}
& F_{f н}(\varphi)=\frac{3}{64} \cdot \frac{m \cdot D_{w}^{2}}{S}\left(\omega_{p 1}^{2}-\omega_{p 0}^{2}\right)-\frac{2 \kappa}{D_{w}} F_{r}(\varphi)+F_{б н}(\varphi) \cdot\left(0,5 \cos \beta_{н}-\frac{h_{H}}{D_{w}}\right)+F_{б в}(\varphi) \cdot\left(0,5 \cos \beta_{\theta}-\frac{h_{\beta}}{D_{w}}\right) . \\
& F_{f \beta}(\varphi)=\frac{3}{64} \cdot \frac{m \cdot D_{w}^{2}}{S}\left(\omega_{p 1}^{2}-\omega_{p 0}^{2}\right)+\frac{2 \kappa}{D_{w}} F_{r}(\varphi)+F_{\sigma н}(\varphi) \cdot\left(0,5 \cos \beta_{\mu}+\frac{h_{H}}{D_{w}}\right)+F_{б в}(\varphi) \cdot\left(0,5 \cos \beta_{\theta}+\frac{h_{\beta}}{D_{w}}\right) .
\end{aligned}
$$




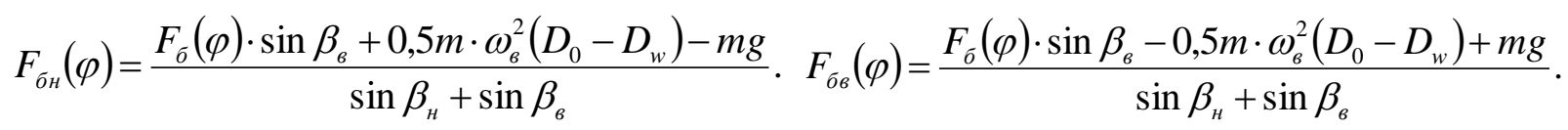

4.2. Кочення ролика на виході із зони навантаження до початку проковзування по внутрішньому кільиі

$$
\begin{aligned}
& m \ddot{x_{c}}=F_{f H}(\varphi)+F_{f \beta}(\varphi)+m g \cdot \sin \varphi-F_{c}(\varphi)-F_{б н}(\varphi) \cdot \cos \beta_{н}-F_{\sigma в}(\varphi) \cdot \cos \beta_{в}+2 F_{r}(\varphi) \cdot \sin \alpha_{i} ; \\
& m \ddot{y_{c}}=m g \cdot \cos \varphi+F_{\sigma н}(\varphi) \cdot \sin \beta_{н}-F_{\sigma в}(\varphi) \cdot \sin \beta_{в}+f \cdot F_{c}(\varphi) \\
& \ddot{I \varphi_{c}}=\left[F_{f H}(\varphi)-F_{f \beta}(\varphi)\right] \cdot \frac{D_{w}}{2}-2 \kappa \cdot F_{r}(\varphi) \cdot \cos \alpha_{i}-F_{б н}(\varphi) \cdot h_{\mu}-F_{6 в}(\varphi) \cdot h_{b}-0,5 D_{w} \cdot f_{c} \cdot F_{c} ;
\end{aligned}
$$

$\frac{3}{16} m \cdot D_{w}^{2}\left(\omega_{p 1}^{2}-\omega_{p 0}^{2}\right)=\left[F_{f u}(\varphi)+F_{f \beta}(\varphi)+m g \cdot \sin \varphi-F_{б н}(\varphi) \cdot \cos \beta_{\mu}-F_{б в}(\varphi) \cdot \cos \beta_{\theta}+2 F_{r}(\varphi) \sin \alpha_{i}\right] \cdot S ;$

$$
\begin{gathered}
F_{\sigma н}(\varphi)+F_{\sigma в}(\varphi)=F_{\sigma}(\varphi) . \\
F_{f_{b}}\left(\varphi, F_{r}(\varphi), F_{\sigma н}(\varphi), F_{\sigma в}(\varphi), F_{c}(\varphi)\right) \leq f_{c} \cdot N(\varphi),
\end{gathered}
$$

де $N(\varphi)=m g \cdot \cos \varphi+F_{\text {бн }}(\varphi) \cdot \sin \beta_{н}-F_{б в}(\varphi) \cdot \sin \beta_{\beta}+F_{r}(\varphi) \cdot \cos \alpha_{i}$.

Розв’язання системи (21) - (26):

$$
F_{c}(\varphi)=\frac{m g(\cos \varphi+0,5 \sin \varphi)-\frac{9}{64} \cdot \frac{m \cdot D_{w}^{2}}{S}\left(\omega_{p 1}^{2}-\omega_{p 0}^{2}\right)-A \cdot C-D \cdot B+S-F_{r}(\varphi) \cdot\left(\frac{2 \kappa}{D_{w}} \cos \alpha_{i}+\cos \alpha_{i}-\sin \alpha_{i}\right)}{f_{c} \cdot(D-C+1,5)+0,5}
$$

де $A=F_{\sigma}(\varphi) \cdot \sin \beta_{\theta}-m g \cdot \cos \varphi+0,5 m \cdot \omega_{6}^{2} \cdot\left(D_{0}-D_{w}\right)$;

$$
\begin{aligned}
& B=F_{\sigma}(\varphi) \cdot \sin \beta_{\theta}+m g \cdot \cos \varphi-0,5 m \cdot \omega_{b}^{2} \cdot\left(D_{0}-D_{w}\right) ; \\
& C=\frac{\left(h_{u} / D_{w}\right)+0,5 \cos \beta_{H}}{\sin \beta_{u}+\sin \beta_{\theta}} ; D=\frac{\left(h_{\theta} / D_{w}\right)+0,5 \cos \beta_{b}}{\sin \beta_{u}+\sin \beta_{s}} ; S=\frac{A \cdot \sin \beta_{u}-B \cdot \sin \beta_{b}}{\sin \beta_{u}+\sin \beta_{\theta}} .
\end{aligned}
$$

\section{5. Розроблення методу розрахунку сепаратора на витривалість при згині \\ Дано: розрахункова модель сепара- тора циліндричного роликопідшипника; необхідно: отримати аналітичні залежності для розрахунку сепаратора циліндричних роликопідшипників на витривалість при}

згині. Ідея розв 'язання - вводиться гіпотеза про плоску деформацію тонких кілець сепаратора; методом сил визначається момент згину в кільцях сепаратора, застосовується умова міцності у формі допустимих напружень, які визначаються через межу витривалості. 
При $0 \leq \theta \leq \alpha$ :

$$
\begin{aligned}
& M(\theta)=-F_{c} \cdot R_{c} \cdot \sin \alpha \cdot \sin \theta-\frac{F_{c} \cdot R_{c} \cdot \cos \theta}{\pi}\left(\sin ^{3} \alpha+\pi \cdot \cos \alpha-\alpha \cdot \cos \alpha+\sin \alpha \cdot \cos ^{2} \alpha\right)+ \\
& \quad+\frac{F_{c} \cdot R_{c}}{\pi}(\pi-\alpha+\sin \alpha),
\end{aligned}
$$

при $\alpha \leq \theta \leq \pi$ :

$$
\begin{gathered}
M(\theta)=-F_{c} \cdot R_{c} \cdot\left\{\left(\sin ^{2} \alpha-\cos \alpha \cdot \cos \theta+\cos ^{2} \alpha\right)+\frac{\cos \theta}{\pi}\left(\sin ^{3} \alpha+\pi \cdot \cos \alpha-\alpha \cdot \cos \alpha+\sin \alpha \cdot \cos ^{2} \alpha\right)-\right. \\
\left.-\frac{1}{\pi}(\pi-\alpha+\sin \alpha)\right\} . \\
\sigma_{F}=-\frac{M(\theta)}{W} \cdot K \leq\left[\sigma_{F}\right], \text { де } \quad K=K_{F} \cdot K_{V} \cdot K_{\sigma} \\
{\left[\sigma_{F}\right]=\sigma_{F_{0}} / S_{F}}
\end{gathered}
$$

\begin{tabular}{|c|c|}
\hline $\begin{array}{l}\text { 6. Розроблення методики розра- } \\
\text { хунку } \\
\text { коефіціснтів }\end{array}$ & $\begin{array}{lcc}\text { динамічності } & \text { взаємодії } & \text { сепаратора } \\
\text { роликами } & \text { спрощеним } & \text { розрахунком }\end{array}$ \\
\hline $\begin{array}{l}\text { навантаження сепаратора роликами, } \\
\text { концентрації навантаження сепаратора, } \\
\text { концентрації напружень в сепараторі }\end{array}$ & $\begin{array}{lrr}\text { ударного } & \text { навантаження; } \\
\text { коефіцієнт } & \text { козначентрації } \\
\text { сепаратора при переконтажені до опорного кільця }\end{array}$ \\
\hline Дано: умови експлуатації, особливості & за гіпотезою \\
\hline $\begin{array}{l}\text { конструкції та кінематики підшипника; } \\
\text { необхідно: розробити методики визначення }\end{array}$ & $\begin{array}{lcc}\text { залежності } & \text { між } & \text { нормальним } \\
\text { навантаженням і контактною деформацією }\end{array}$ \\
\hline $\begin{array}{l}\text { складових коефіцієнта навантаження } \\
\text { сепаратора для розрахунку напружень. Iдея }\end{array}$ & $\begin{array}{l}\text { визначається концентрація напружень } \\
\text { конструкції сепаратора методом скінчени }\end{array}$ \\
\hline
\end{tabular}

6.1. Коефіиієнт динамічності навантаження сепаратора роликами

$$
\begin{gathered}
V_{p} \cdot m_{p}+V_{c} \cdot m_{c}=V_{p c} \cdot\left(m_{p}+m_{c}\right), \\
V_{p}=\frac{V \cdot d_{B}}{4 R} ; \quad V_{c}=\frac{V \cdot d_{B}}{4 R}\left[\left(1-\frac{2 S_{0}}{d_{0} \cdot \psi}\right)\left(\frac{m_{p}}{m_{c}}+1\right)-\frac{m_{p}}{m_{c}}\right] ; \quad V_{p c}=V_{p} \cdot\left(1+\frac{2 S_{0}}{d_{0} \cdot \psi}\right) . \\
T=\Pi-\Pi^{*}, \\
T=0,5\left(m_{p}+m_{c}\right)\left(V_{p}-V_{c}\right)^{2} ; \quad \Pi=0,5 c \cdot f_{\text {дин }}^{2} ; \quad \Pi^{*}=\left(m_{p}+m_{c}\right) \cdot g \cdot f_{\text {дин }} \\
f_{\text {дин }}^{2}-2 f_{c m} \cdot f_{\text {дин }}-\frac{f_{c m}}{g}\left(V_{p}-V_{c}\right)^{2}=0,
\end{gathered}
$$




$$
\begin{gathered}
f_{\text {дин }}=f_{c m} \cdot K_{V}, \\
K_{V}=1+\sqrt{1+\frac{5,03 E \cdot b \cdot h^{3} \cdot\left(V_{p}-V_{c}\right)^{2}}{D_{0}^{3} \cdot g^{2} \cdot\left(m_{p}+m_{c}\right)} .}
\end{gathered}
$$

\section{2. Коефіцієнт концентрації навантаження сепаратора}

$$
K_{F}=\frac{q_{\max }}{q_{u}}=1+\frac{3 e}{l_{\kappa}} .
$$

7. Удосконалення методу розрахунку ймовірності безвідмовної роботи підшипника з урахуванням витривалості сепаратора

Дано: межа витривалості сепаратора i напруження згину в сепараторі; необхідно: удосконалити метод розрахунку ймовірності безвідмовної роботи підшипника кочення за контактновтомними пошкодженнями. Ідея розв'язання - пропонується ймовірність безвідмовної роботи підшипника подавати як добуток відповідних ймовірностей за контактно-втомним пошкодженням i втомним руйнуванням сепаратора; за експериментом визначається межа витривалості сепараторів, розраховуються коефіцієнти варіації межі витривалості і напружень згину сепаратора.

$$
\begin{gathered}
P=P_{L} \cdot P_{F} \cdot \\
u_{p L}=-\frac{\overline{n_{L}}-1}{\sqrt{\overline{n_{L}^{2}} \cdot v_{c}^{2}+v_{p}^{2}}}, \overline{n_{L}}=\frac{\bar{c}}{\bar{p} \cdot L^{1 / p}} . \\
u_{p F}=-\frac{\overline{n_{F}}-1}{\sqrt{\overline{n_{F}^{2}} \cdot v_{\sigma}^{2}+v_{\Sigma}^{2}}}, \overline{n_{F}}=\frac{\overline{\sigma_{F 0}}}{\sigma_{F}}, \text { де } \\
M=-\frac{M \cdot R}{\pi}\left(\sin ^{3} \alpha+\pi \cdot \cos \alpha-\alpha \cdot \cos \alpha+\sin \alpha \cdot \cos ^{2} \alpha-\sin \alpha-\pi+\alpha\right) . \\
W \quad, K_{V}, \text { тут } \\
v_{\Sigma}=\sqrt{v_{F}^{2}+v_{V}^{2}}, \quad,
\end{gathered}
$$




$$
\begin{gathered}
\text { де } v_{F}=S_{F} / \overline{K_{F}} ; v_{V}=S_{V} / \overline{K_{V}} ; \text { тут } S_{F}=\left(K_{F \max }-K_{F \min }\right) / 6 ; \overline{K_{F}}=0,5\left(K_{F \min }+K_{F \max }\right) ; \\
S_{V}=\left(K_{V \max }-K_{V \min }\right) / 6 ; \overline{K_{V}}=0,5\left(K_{V \min }+K_{V \max }\right) . \\
v_{\sigma}=\frac{S_{\sigma}}{\overline{\sigma_{F 0}}}, \text { де } S_{\sigma}=\left(\sigma_{F 0 \max }-\sigma_{F 0 \min }\right) / 6 .
\end{gathered}
$$

\section{Висновки:}

1. Виявлено дотичні сили на доріжках кочення кілець.

2. Визначено розподіл осьової сили при будь-яких ексцентриситетах осьового i радіального навантажень підшипника 3 розрахунковим кутом перекосу кілець.

3. Запропоновано механізм передачі руху від роликів до сепаратора та методику визначення середньої швидкості сепаратора.

4. Запропоновано розрахункову
5. Запропоновано метод розрахунку сепаратора роликопідшипника на витривалість при згині з урахуванням конструктивних і експлуатаційних факторів.

6. Запропоновано методики визначення коефіцієнтів динамічності навантаження сепаратора роликами, концентрації навантаження при перекосі, концентрації напружень.

7. Запропоновано метод розрахунку ймовірності безвідмовної роботи підшипника 3 урахуванням опору втомі сепаратора. модель сепаратора.

\section{Сиисок літератури}

1. Мельничук, В.А. К вопросу повышения надёжности буксовых узлов с подшипниками качения [Текст] / В.А. Мельничук, А.В. Донченко, И.Э. Мартынов // Залізничний транспорт України. - 2002. - №5. - С. 34-37.

2. Волков, Н.Н. Подшипники качения колесных пар вагонов и локомотивов [Текст] / Н.Н. Волков, Н.В. Родзевич. - М.: Машиностроение, 1972. - 168 с.

3. Андриевский, В.Г. Влияние зазоров в гнездах сепараторов на работу деталей подшипника качения [Текст] / В.Г. Андриевский, А.В. Гайдамака, С.М. Шнырь // Подшипниковая промышленность. - 1983. - № 2. - С. 3-9.

4. Гайдамака, А.В. О причинах появления сил между телами качения и сепаратором в подшипниках [Текст] / А.В. Гайдамака // Зб. наук. праць. - Харків: УкрДАЗТ, 2003. Вип. 54. - С. 111-116.

5. Аверин, Н.А. Исследование нагруженности буксовых подшипников локомотивов при эксплуатации с повышенными осевыми нагрузками [Текст]: автореф. дис... канд. техн. наук: 05.22.07 / Н.А. Аверин. - М., 1982. - 19 с.

6. Акбашев, Б.3. Некоторые итоги экспериментального исследования работы сепараторов цилиндрических роликоподшипников локомотивов [Текст] / Б.З. Акбашев, P.М. Девин // Подшипниковая промышленность. - 1969. - № 3.- С. 10.

7. Лосев, А.В. Исследование работы сепараторов железнодорожных роликовых подшипников при высоких скоростях движения [Текст]: автореф. дис... канд. техн. наук: 05.22.07 / А.В. Лосев. - М., 1972. - 21 с.

8. Шавшишвили, А.Д. Исследование работоспособности подшипников качения букс вагонов, предназначенных для эксплуатации со скоростями движения до 200 км/ч [Текст]: автореф. дис... канд. техн. наук: 05.07.22 / А.Д. Шавшишвили. - М., 1981. - 23 с. 
9. Цюренко, В.Н. Надежность роликовых подшипников в буксах вагонов [Текст] / В.Н. Цюренко, Петров В.А. - М.: Транспорт, 1982. - 96 с.

Ключові слова: підшипник, радіальне, осьове навантаження.

\section{Анотаціï}

Наведено результати удосконалення моделей розподілу радіального та осьового навантаження між тілами кочення підшипника, а також результати розроблення моделей кінематики та динаміки деталей в зоні навантаження підшипника для методів розрахунку сепаратора на витривалість при згині і розрахунку ймовірності безвідмовної роботи підшипника з урахуванням опору втомі сепаратора.

Представлены результаты усовершенствования моделей распределения радиальной и осевой нагрузок между телами качения подшипника, а также результаты разработки моделей кинематики и динамики деталей в зоне нагружения подшипника для методов расчёта сепараторов на выносливость при изгибе и расчёта вероятности безотказной работы подшипника с учётом сопротивления усталости сепаратора.

In article results of improvement of models of distribution of radial and axial loadings between bodies of swing of the bearing and development of models of kinematics and dynamics of details are given in a zone of loading of the bearing for methods of calculation of separators on endurance at a bend and calculation of probability of no-failure operation of the bearing taking into account resistance of fatigue of a separator. 